\title{
Emotional Intelligence and Job Engagement of Nurses of Level 1 District Hospitals in Negros Occidental
}

\author{
Jason G. Liansing ${ }^{1}$ and Sheila P. Arnibal ${ }^{2}$ \\ ${ }^{1}$ Don Salvador Benedicto Memorial Hospital, La Carlota City, Negros Occidental, Philippines \\ ${ }^{2}$ University of Negros Occidental-Recoletos, Bacolod City, Philippines
}

\begin{tabular}{l} 
Article history \\
Submitted: 2 November 2020 \\
Revised: 10 November 2020 \\
Accepted: 13 November 2020 \\
\hline Keywords \\
Nursing \\
Emotional Intelligence \\
Job Engagement \\
Nurses \\
Public Hospitals \\
Descriptive-Correlational \\
Negros Occidental
\end{tabular}

Introduction. Emotional Intelligence (EI) has been established as an essential component in success, along with Intelligence Quotient (IQ). Emotional Intelligence is vital in making or maintaining Job Engagement (JE). Dealing with different emotions daily, nurses with low EI are prone to compassion fatigue and job disengagement. Job engagement is essential in ensuring that the quality of care rendered is high, and the patient's safety is guaranteed. Emotional Intelligence plays a vital role in making sure that nurses have a sense of purpose and, in turn, making them more engaged in their daily duties and responsibilities. Hence, this paper describes the level of Emotional Intelligence and Job Engagement of Nurses in Level 1 District Hospitals in Negros Occidental. Likewise, it explores the relationship between Emotional Intelligence and Job Engagement of nurses' demographics and the factors that made them stay in the nursing service. Also, it determines the correlation of EI and JE of nurses; and whether EI affects the level of JE.

Methods. A descriptive, comparative, and correlational research design was used to assess, compare, and correlate EI and JE of nurses of level 1 District Hospitals in Negros Occidental. Using stratified random sampling, 60 nurses participated in the study. The respondents of the survey are the nurses who work in level 1 District Hospitals with their respective areas, such as Pediatric Ward, Medical Ward, Isolation Ward, and other wards. The data were gathered using a standardized questionnaire devised by the National Health Service (NHS) and Decision Wise. Mean, Standard Deviation, Mann Whitney $U$ test, and Spearman Rank Correlation were used to analyze the data.

Results. The findings of the study revealed that EI among nurses who work at a level 1 District Hospitals is very high regardless of their age, sex, years of service, employment status, and education. Their JE yields a top result irrespective of their age, sex, years of service, employment status, and education. As to the relationship between demographics, EI, and JE, the findings revealed a significant relationship between EI and JE. The result also found a correlation between EI and JE; although EI correlates with JE, it is not the sole predictor of JE. The findings revealed that among the factors in staying engaged, family, and salary yielded the highest results. Simultaneously, organizational leaders' commitment is tied with a good and healthy relationship with supervisors and excellent communication, which yielded the lowest score.

Conclusion. During these difficult and uncertain times, EI has never been as essential as it is today. Having high EI also translates to Job Engagement, which minimizes the error and mortality rate in the workplace. The study revealed that the nurses of level 1 District Hospitals have a high EI. The high level of EI indicates that the nurses have a very high level of self-awareness, can manage their emotions very well, are highly motivated, practice empathy, and have excellent social skills. Furthermore, the JE of the nurses is high, which made them see their job positively, are happy with their job, and positively work to meet the demands of the situation, the organization, the supervisors, and the whole health care team. A challenge to the organizational leaders is presented due to the findings that nurses saw the commitment of their corporate leaders and excellent communication insufficient. Organizational leaders must step up, ensure that their subordinates are heard and treated equally, and have a significant role in increasing or maintaining EI and JE in their respective organizations. Although EI is correlated with JE, there are other factors in which JE is achieved and 
maintained. Having a high EI leader will benefit the subordinates substantially. Having one with low EI will cost the organization, resulting in medical error and low quality of patient care.

Practical Value of the Paper. The study significantly contributes to the literature on EI and JE of nurses in level 1 District Hospitals in Negros Occidental. The findings also provided baseline information to the Head nurses and organizational leaders in assessing and maintaining the level of EI of nurses and, in turn, elevating their JE as well. Also, to the future researcher, this will serve as evidence-based data to further investigate the limitations of this study and the importance of acknowledging and incorporating EI in the workplace.

\section{References}

Codier, E., Kamikawa, C., Kooker, B. M., \& Shoultz, J. (2009). Emotional intelligence, performance, and retention in clinical staff nurses. Nursing administration quarterly, 33(4), 310-316.

Dempsey, C., \& Reilly, B. (2016). Nurse engagement: What are the contributing factors for success. OJIN: The Online Journal of Issues in Nursing, 21(1).

Hetzel-Riggin, M. D., Swords, B. A., Tuang, H. L., Deck, J. M., \& Spurgeon, N. S. (2020). Work engagement and resiliency impact the relationship between nursing stress and burnout. Psychological Reports, 123(5), 1835-1853.

Mazzella Ebstein, A. M., Sanzero Eller, L., Tan, K. S., Cherniss, C., Ruggiero, J. S., \& Cimiotti, J. P. (2019). The relationships between coping, occupational stress, and emotional intelligence in newly hired oncology nurses. Psychooncology, 28(2), 278-283.

Raghubir, A. E. (2018). Emotional intelligence in professional nursing practice: A concept review using Rodgers's evolutionary analysis approach. International journal of nursing sciences, 5(2), 126-130.

Ravikumar, R., Rajoura, O. P., Sharma, R., \& Bhatia, M. S. (2017). A study of emotional intelligence among postgraduate medical students in Delhi. Cureus, 9(1).

Sharma, A., Goel, A., \& Sengupta, S. (2017). How does work engagement vary with employee demography?:Revelations from the Indian IT industry. Procedia computer science, 122, 146-153.

Suehs, D. (2015). Emotional intelligence and employee engagement: A quantitative study to explore the relationship between the emotional intelligence of frontline managers and supervisors and the degree of employee engagement of their direct reports in a tertiary care health care setting.

Toyama, H., \& Mauno, S. (2017). Associations of trait emotional intelligence with social support, work engagement, and creativity in Japanese eldercare nurses. Japanese Psychological Research, 59(1), 14-25.

Vestal, A. B. E. (2015). The relationship between nurses' emotional intelligence and their perceived work performance. University of the Visayas-Journal of Research, 9(1), 115-124.

\section{Correspondence:}

Jason G. Liansing [jasonliansing@gmail.com]

https://orcid.org/0000-0002-5660-1484 